\title{
Desdobramento da violência no trabalho: a experiência de gestores da Enfermagem
}

\author{
Unfolding of violence at work: the experience of Nursing managers \\ Despliegue de la violencia en el trabajo: la experiencia de gestores de Enfermería
}

Recebido: 13/06/2021 | Revisado: 24/06/2021 | Aceito: 01/07/2021 | Publicado: 14/07/2021

Ellen Maria Hagopian

ORCID: https://orcid.org/0000-0001-5966-0159

Universidade de São Paulo, Brasil

E-mail: ellenmaria@usp.br

Genival Fernandes de Freitas

ORCID: https://orcid.org/0000-0003-4922-7858

Universidade de São Paulo, Brasil

E-mail: genival@usp.br

\begin{abstract}
Resumo
Objetivos: compreender o cotidiano de gestores da Enfermagem sobre a violência no ambiente de trabalho; relacionar as estratégias gerenciais com os comportamentos disruptivos na equipe de Enfermagem. Método: trata-se de uma pesquisa descritivo-exploratória com abordagem qualitativa. Foram entrevistados cinco gestores da área da Enfermagem por meio de entrevistas gravadas com questões norteadoras. Resultados: a partir dos discursos, emergiram três categorias: "Articular ações diante das relações de poder"; "Dialogar e acolher diante das situações adversas"; "Importância do apoio da alta gestão". Conclusão: a análise dos discursos permitiu compreender a experiência de gestores de Enfermagem nos seus distintos ambientes laborais em relação a situações que envolvem riscos à saúde do trabalhador e a qualidade e segurança da assistência prestada.
\end{abstract}

Palavras-chave: Violência no trabalho; Enfermagem; Liderança.

\begin{abstract}
Objectives: understand the daily lives of nursing managers regarding violence in the work environment; relate managerial strategies with disruptive behaviors in the nursing team. Method: this is a descriptive-exploratory research with a qualitative approach. Five managers from the Nursing area were interviewed by means of recorded interviews with guiding questions. Results: from the speeches, three categories emerged: "Articulate actions in the face of power relations"; "Dialog and welcome when faced with adverse situations"; "Importance of support from top management". Conclusion: the analysis of the speeches allowed us to understand the experience of nursing managers in their different work environments in relation to situations that involve risks to workers' health and the quality and safety of the care provided.
\end{abstract}

Keywords: Workplace violence; Nursing; Leadership.

\section{Resumen}

Objetivos: comprender la vida diaria de los gestores de Enfermería sobre la violencia en el ambiente de trabajo; relacionar las estrategias de gestión con las conductas disruptivas en el equipo de Enfermería. Método: se trata de una investigación descriptiva-exploratoria con enfoque cualitativo. Se entrevistaron cinco gestores del área de Enfermería a través de entrevistas grabadas con preguntas orientadoras. Resultados: de los discursos surgieron tres categorías: "Articular acciones frente a las relaciones de poder"; "Dialogar y acoger ante situaciones adversas"; "Importancia del apoyo de alta gestión". Conclusión: el análisis de los discursos permitió comprender la experiencia de gestores de Enfermería en sus diferentes entornos laborales en relación a situaciones que involucran riesgos para la salud del trabajador y la calidad y seguridad de la atención brindada.

Palabras clave: Violencia en el trabajo; Enfermería; Liderazgo.

\section{Introdução}

A vulnerabilidade social, nos tempos atuais, bem como a desestabilização no ambiente de trabalho, compromete a estrutura social na atividade laboral da equipe de Enfermagem. Infere-se, dessa forma, uma série de malefícios do trabalho precário, em especial, na vida profissional e social do trabalhador, que se vê cada vez mais desprotegido do ponto de vista social com relação aos seus direitos. 
À sombra de um movimento político intenso para que a precarização perdure por meio da flexibilização dos vínculos dos trabalhadores, recorre-se à seriedade com a qual a violência no trabalho deva ser imprescindivelmente discutida, analisada e mapeada em todas as esferas profissionais como fator de risco psicossocial à vida do trabalhador da Enfermagem. Este representa $60 \%$ da força de trabalho total na área da saúde, porcentagem que, no Brasil, corresponde a 1.800 .000 trabalhadores (Machado et al., 2016).

Nas instituições hospitalares, este movimento configura-se pautado em relações de medo cujas características de dominação reverberam em: insegurança; competição; desconfiança e individualismo; constrangimento e sequestro do tempo e da subjetividade do trabalhador.

Os conceitos sobre a violência no trabalho são mostrados para uma ampla gama de situações. A Occupational, Health and Security Administration (OSHA) - (Administração de Segurança e Saúde Ocupacional, 2016) define como violência no trabalho:

"Violência no local de trabalho é qualquer ato ou ameaça de violência física, assédio, intimidação ou outro comportamento disruptivo ameaçador que ocorra no local de trabalho. Varia de ameaças e abuso verbal a agressões físicas e até homicídio. Pode afetar e envolver funcionários, clientes e visitantes."

A violência denominada como institucionalizada configura-se nas relações contemporâneas de trabalho fortemente capitalistas e com metas lucrativas. Tal violência degrada e controla os comportamentos, modos de pensar e as decisões do trabalhador vitimado (Hashizume, 2014).

A violência institucional, ocultada por interesses financeiros, traz sérios prejuízos à organização com a destruição do clima de trabalho, o aumento geral do sentimento de insegurança e o consequente bloqueio da criatividade. $\mathrm{O}$ trabalhador sente-se desamparado em meio a uma infinidade de cobranças, pressões e estresses exacerbados que, por vezes, conflitam com seus critérios éticos e valores pessoais.

Independentemente do conceito estabelecido, é necessário compreender que o desajuste na relação de violência e trabalho, por meio da deterioração das condições e organização, suscita sofrimentos, desgastes, fadigas, adoecimentos físicos e psíquicos e pode levar ao suicídio. Na perspectiva do domínio ideológico, as empresas estabelecem convicções, valores, objetivos e metas que os trabalhadores assumem como pessoais. Contrários à ideia de repressão propriamente dita, existem os modelos gerencialista e narcisista nos quais a onipotência torna o trabalhador mobilizado e aderido às políticas internas da instituição (Pagés et al., 2005).

A vigilância passa a ser subjetiva, ou seja, o trabalhador torna-se controlador de si próprio mediante exposições externas, o que remete a maiores níveis de estresse, desgastes e adoecimentos, em destaque, os psíquicos. Por ocasião de um erro, um projeto fora do prazo, uma criatividade não exposta, o profissional sente-se culpado, frustrado e impotente para questionar (D'Aubeterre, 2009).

$\mathrm{Na}$ área da Enfermagem, o papel do gestor é muito expressivo porque apresenta denominações distintas conforme a estrutura organizacional da instituição. São intitulados como chefes, chefias, encarregados, supervisores, gerentes, assessores, coordenadores, entre outros, os que representam, frente a uma equipe de tralhado que presta assistência ao usuário de saúde, um papel hierarquicamente superior. Por isso, na área da Enfermagem, o papel do líder tem determinados objetivos em uma prática social que configura a Enfermagem como: planejamento; dimensionamento de pessoal; recrutamento e seleção; educação continuada e/ou permanente; supervisão e avaliações periódicas de desempenho; previsão e provisão de recursos materiais e estruturais.

Nessa perspectiva, os gestores têm papel fundamental na construção da produção em saúde e em como coordenar condições adequadas de organização do trabalho dos profissionais da categoria, pois reverberam na assistência direta aos 
usuários do sistema. As estratégias para a mediação das tantas relações estabelecidas na prática social do líder incluem quatro dimensões: (Almeida et al., 1994)

- Técnica: planejamento, coordenação, supervisão, controle e avalição de recursos humanos, materiais e físicos para a execução do trabalho;

- Política: articula o trabalho gerencial ao projeto que se tem a empreender;

- Comunicativa: configura a negociação ao lidar com as distintas e diversas relações de trabalho na equipe de Enfermagem e de saúde como um todo;

- Desenvolvimento da cidadania: implica tomar a gerência como uma atividade que contém perspectiva de emancipação dos sujeitos sociais para os trabalhadores como os usuários.

Para lançar luz à violência no trabalho, inspecionar, prevenir e erradicá-la, é necessário que as empresas públicas e/ou privadas tomem consciência de suas responsabilidades, e é necessária a avaliação dos riscos e fatores psicossociais. As formas de gestão devem ser praticadas por meio do diálogo; na exigência do respeito e reconhecimento ao outro; na promoção justa; no estabelecimento de uma política de metas e produção compatível com o trabalho, digna e saudável para todos os trabalhadores.

Em pesquisa na qual foi mapeado o perfil da Enfermagem no Brasil, destacaram-se os porcentuais inferiores e preocupantes da clientela usuária, com índices baixos, que mostraram que menos da metade da equipe de Enfermagem (47,2\%) recebe tratamento cordial e respeitoso nos momentos relacionais no ambiente de trabalho (Machado et al., 2016).

Machado et al. (2016) referiram que os estrangulamentos relacionais do trabalho emergem de posicionamentos contraditórios que permeiam as relações de trabalho, cercadas de confrontos e conflitos por causa da assimetria de interesses e divisão social do trabalho, no interior de seus processos. Portanto, surgem os desgastes psicológico, emocional e orgânico que se iniciam sob sintomas, por vezes, imperceptíveis e têm tomado proporção anormal entre os trabalhadores que lidam com o cuidado.

Deve-se buscar, assim, a causalidade não somente na raiz dos problemas, mas, em especial, submergindo nas entranhas da relação capital e trabalho e encontrar as suas contradições. Excluir essa dimensão é abstrair-se: da realidade concreta; das condições laborais estabelecidas e vetores psicossociais assumidos; da cultura organizacional que induz a reprodução de ações não éticas de senso comum.

Como objetivo do estudo proposto cita-se: compreender o cotidiano de gestores da Enfermagem quanto à violência no ambiente de trabalho.

\section{Metodologia}

Para o desenvolvimento do estudo, optou-se pela pesquisa descritivo-exploratória com abordagem qualitativa. Segundo Minayo (2013), a pesquisa descritiva objetiva descobrir a frequência com que um uma ação ocorre, sua natureza, características, causas, relações e conexões com outros fatos.

Medeiros (2008) acrescentou que a pesquisa descritiva abrange não somente descobrir e observar os fenômenos, mas descrevê-los, classificá-los e interpretá-los.

Os estudos exploratórios propõem evidenciar eventos pouco conhecidos com o intuito de viabilizar um alcance de pesquisa com maior completude, além de explorar novos problemas, conceitos ou variáveis. Teixeira (2008) afirmou que, ao aumentar a experiência em torno de um determinado problema e procurar reduzir a distância entre a teoria e os dados, se pode enfatizar o processo dos acontecimentos.

A abordagem qualitativa demonstrou ser a mais adequada para alcançar os objetivos propostos na medida em que permite captar aspectos subjetivos e motivações não explícitas, pois, como informou Minayo (2013, p. 24): 
"A pesquisa qualitativa responde a questões muito particulares, [...] trabalha com o universo de significados, motivos, aspirações, crenças, valores e atitudes, o que corresponde a um espaço mais profundo das relações, dos processos e dos fenômenos."

A pesquisa qualitativa permitirá compreender e aprofundar os elementos explorados a partir das perspectivas dos gestores de Enfermagem, em distintas áreas de atuação de hospitais públicos do município de São Paulo, relacionados com a violência no trabalho e seus desdobramentos como risco psicossocial para o trabalhador.

A população do estudo refere-se a gestores que são ou foram inseridos à frente da gestão de áreas de Enfermagem e que seus cargos configurem situação hierárquica superior aos outros trabalhadores na área da Enfermagem, por exemplo: gestor; líder; coordenador; encarregado; cargo de chefia; supervisor; assessor, entre outros e possuir, no mínimo, cinco anos de atuação no cargo especificado.

A amostra foi composta por cinco gestores da área da Enfermagem que atuam frente à diretoria dos serviços de Enfermagem. Foram realizadas entrevistas semiestruturadas por meio de questões norteadoras que articulam o universo vivenciado pelos gerentes de Enfermagem diante das estratégias institucionais e do relacionamento com a equipe de Enfermagem e foi aplicado, também, um questionário sociodemográfico com o objetivo de caracterizar a amostra e, posteriormente, analisar os dados.

Para a análise dos dados, utilizou-se a análise do discurso, abordagem que permite compreender a multiplicidade de sentidos que o sujeito manifesta e considera, ao mesmo tempo, os elementos presentes no contexto de sua elaboração com relação à vivência dos gerentes de Enfermagem no contexto da violência laboral.

Por tratar-se de um estudo com seres humanos, o projeto foi submetido ao Comitê de Ética em Pesquisa da Instituição Proponente para atender à Resolução $n^{\circ} 446 / 12$ do Conselho Nacional de Saúde e foi aprovado pelo número CAEE ${ }^{\circ}$ 17997319.8.0000.5392.

\section{Resultados}

Foram entrevistados cinco gestores conforme os critérios de inclusão designados na pesquisa. O tempo médio de entrevista foi de 28 minutos e oito segundos e o tempo de formação média dos entrevistados é de 40 anos e oito meses. Relacionado ao gênero, um entrevistado é do sexo masculino e as demais, que totalizam quatro, são do sexo feminino. Para a identificação dos entrevistados, respeitando as questões éticas de anonimato, estes foram referidos por numeração, sendo Gestor 1, Gestor 2 e assim por diante.

Diante das análises das entrevistas, emergiram três categorias que relatam as vivências desses gestores frente às situações de violência no ambiente de trabalho e seus enfrentamentos por meio da utilização de instrumentos gerenciais: "Articular ações diante das relações de poder"; "Dialogar e acolher diante das situações adversas"; "Importância do apoio da alta gestão".

Compreender o cotidiano de gestores da Enfermagem quanto à violência no ambiente de trabalho faz emergir, nos profissionais que se posicionam frente à liderança da equipe, uma variedade de sentimentos e reflexões acerca de atitudes e situações que podem degradar o ambiente laboral, assim como o direcionamento para cercear tais circunstâncias.

As relações de poder são discursadas nos depoimentos como um fato inerente à história da criação do hospital e presente entre os profissionais da saúde, destacando-se a figura médica como centralizadora do poder.

Nessa direção, Michel Foucault (1988, p. 109-10) assinalou que “[...] o médico é anunciado por uma sineta e esperado pela enfermeira na porta da enfermaria com um caderno nas mãos, para segui-lo quando entrar". Ora, torna-se possível o entendimento de que as relações entre médico e enfermeira demandam certo jogo de dependência e subordinação de um ator 
em relação ao outro, pois, enquanto a enfermeira "segue" o médico, este depende da presença quase ininterrupta da primeira para garantir a continuidade da assistência e da cura.

A ênfase acentuada nos aspectos morais e de caráter e a técnica disciplinar, que sustentam o modelo vocacional preconizado por Florence Nightingale, buscavam assegurar a realização da imagem pública da mulher que executava o trabalho de cuidar dos doentes.

[...]o treinamento que constituía a formação do futuro profissional baseava-se, segundo Florence, na capacidade de executar fielmente ordens médicas e de autoridades. Esta subordinação da enfermeira ao médico aparece reiteradas vezes em textos de Florence. Portanto, a enfermagem profissional foi concebida como dependente e subordinada à prática médica" (Gastaldo, Meyer, 1989, p. 9).

O poder se centraliza no médico, mormente no âmbito hospitalar. Isso é uma coisa que devemos aprender a lidar. (Gestor 1)

Tive que interferir em alguns problemas entre esses profissionais. Chamava o médico e mostrava o que realmente tinha acontecido e ele assumia que realmente estava errado. (Gestor 2)

[...] eu não criava essa diferenciação, essa distância, essa hierarquia verticalizada e essa sensação de 'Estou no poder. Eu mando e vocês obedecem'! Não, não era dessa forma. Toda vez que eu determinava que uma tarefa fosse realizada de tal forma e observava que a pessoa desempenhava incorretamente, eu mesma a executava como sendo uma forma de dar o exemplo, demonstrando a ela que era possível fazer corretamente. (Gestor 4)

Costumava dizer que, dentro de uma instituição, o gestor era e é o norteador. Ele deve medir suas palavras, tomar cuidado com seu comportamento, dar o exemplo e não se utilizar do poder para desviar as atitudes corretas a fim de situações não éticas no ambiente de trabalho. (Gestor 4)

[...] minimizar essa distância entre os conceitos e as ações que causavam tanto medo, pavor e fofoca. Tudo tinha de ser muito transparente, muito honesto e com muito respeito. (Gestor 2)

Trabalhávamos com muita transparência, com muita lealdade, o que fez com que estabelecêssemos um vínculo de segurança e de confiança mútua, portanto, nunca tive problemas. (Gestor 1)

$\mathrm{O}$ acolhimento por meio do diálogo aberto foi notado como um método harmonioso em que o respeito é pleiteado nas relações laborais e propulsor para a resolução de questões problemáticas.

Como diretora, procurava saber o que estava acontecendo entre o médico e o enfermeiro e nos reuníamos para uma reunião. Tais acontecimentos ocorreram por várias vezes, mas sempre teve um bom desfecho. (Gestor 4)

[...] os dois se articularam e compreenderam o ponto de vista de cada um. Por um lado, eu tentava articular e denotar a responsabilidade que cada um tinha no processo cuidativo. (Gestor 4)

Nunca foi uma coisa acintosa, sempre foi construtiva - esse é o ponto essencial. Ademais, nunca usei meu cargo para abusar - esse sempre foi meu primeiro princípio. Ouço muito, racionalizo e tento compreender da melhor forma possível e procuro sempre agir de forma agradável. (Gestor 3)

Houve situações em que consegui ter uma boa conversa. Se você consegue abordar aquele problema e discutir com as pessoas, já valeu. (Gestor 5)

Enquanto gestora, vivenciei experiências de sofrimento e violência entre os pacientes, profissionais e chefia. A mais grave foi o caso de uma mãe que verbalizou violentamente contra uma funcionária do Berçário, o que a deixou muito chocada. Abrimos um Boletim de Ocorrência (BO), pois houve agressão física. Vimos o lado da mãe, que estava passando por um momento difícil, visto que ela apresentava transtorno pós-parto e depressão; contudo, nada justifica 
a agressão, claro. Acolhemos a funcionária e tivemos a cautela de encaminhá-la ao psicólogo do próprio hospital. (Gestor 3)

Além dos casos que citei, presenciei, em vários momentos, violência verbal entre chefia de Enfermagem e funcionário. Lidar com isso é muito complicado! Conquanto, usamos da escuta, acordo e empatia. (Gestor 4)

Sempre devemos acolher. A escuta e o acolhimento são imprescindiveis. Acredito que os profissionais devam trabalhar em um local tranquilo porque somos gente que cuida de gente. Se estivermos em um ambiente desagradável, desprovido de profissionais e que se sentem pressionados, pequenos conflitos surgirão no cotidiano e poderão causar sofrimentos. (Gestor 1)

Penso que quanto mais se é coerente no discurso e em suas ações, mais chances existem de minimizar as situações problemáticas, por isso, sempre me atentei a ter uma boa comunicação. (Gestor 5)

Nossas iniciativas ainda são incipientes e, mesmo embasadas nas pesquisas que realizamos, percebo que poderíamos fazer mais, ter políticas mais efetivas e ampliadas. Entretanto, existe pouca abertura para a concretização desses ideais, mormente à informalidade inerente ao acolhimento e atendimento realizado pelos psiquiatras e psicólogos. É um esforço constante que precisamos fazer no sentido de valorizar o funcionário nesse aspecto; no entanto, tenho boas perspectivas. (Gestor 2)

A importância do apoio da alta gestão nas questões que envolvem a violência no ambiente de trabalho e/ou que propiciam um ambiente não saudável para se trabalhar foi apontada como primordial para o alcance desse ambiente.

Em alguns hospitais, ocorrem sérios problemas entre enfermeiros e outros profissionais, mas isso tudo depende da forma como a direção atua. Se a direção não abre para a discussão, causa problemas e isso reflete nos funcionários. O grupo deve ser articulado e perceber a instituição como um futuro para ele e para os outros. Se a direção promove um ambiente de compreensão e de discussão construtiva, tudo isso se monitoriza sozinho. (Gestor 2)

No fim do ano passado, desenvolvemos um curso de violência não verbal para toda a chefia no qual trouxe a vivência da própria realidade relacionada à dificuldade em lidar nesse contexto. Um item da pauta desta reunião se dirigia às falhas de comunicação, inclusive, no uso da própria tecnologia, como, por exemplo, o WhatsApp. Toda essa ação foi apoiada pela diretoria. (Gestor 1)

O tipo de mercadoria que entrego tem consequência imediata e torna visivel a falha do processo de trabalho. Existe, claro, um grau de tensão bem maior. Portanto, se replico uma estrutura que não valoriza o trabalhador, reproduzo a violência. Além disso, acredito que, para atenuar a violência no ambiente de trabalho, é necessário reduzir a distância e recordar o real papel do enfermeiro.

Eu vivi uma época, no início de minha carreira, como gestora em que os profissionais não tinham o direito de se mobilizarem e de se entristecerem por motivos pessoais. O discurso de que 'os seus problemas você larga na porta ao entrar no trabalho' - era muito presente. Se o trabalhador tivesse um sofrimento físico, como uma cefaleia, uma gripe ou um mal-estar, não poderia verbalizar isso, senão era rechaçado pela chefia. A instituição tinha uma postura muito militar. (Gestor 4)

Enfrentei uma gestão extremamente agressiva a ponto de escarnecer profissionais publicamente - este cenário era bastante recorrente. Ao mesmo tempo em que existia essa condição dentro do trabalho, por outro, tinha-se uma permissividade para que os próprios profissionais promovessem o bullying entre eles. Era um ambiente de muita conversa paralela, fofoca e comentários uns dos outros que infringiam fortemente a questão da ética e do relacionamento profissional. Acredito que toda essa situação possa ser amenizada elou fomentada pela alta direção. (Gestor 3) 


\section{Discussão}

Segundo Felli et al. (2015), as condições de trabalho favorecem e ou potencializam processos de desgaste, comprometendo, além do bem-estar e da saúde do trabalhador, a assistência prestada à população. $\mathrm{O}$ adoecimento está relacionado, dentre outros aspectos, à exposição a fatores agravantes, que promovem o mal-estar físico e mental, como é o caso do estresse, da tensão, das relações interpessoais assimétricas, da dificuldade de comunicação, da sobrecarga e do ritmo acelerado de trabalho e da falta de reconhecimento.

O ensejo dos trabalhadores com muitas exigências apresenta redução da capacidade de trabalho diante do contato diário com situações altamente tensiogênicas. O eco deste cenário reflete diretamente na saúde dos trabalhadores, bem como é função do processo de trabalho que leva à redução da autonomia e da tomada de decisão. É urgente a necessidade de repensar as práticas cotidianas do trabalho em saúde em processos de Enfermagem ao considerar a inclusão de medidas que aliviem a tensão no trabalho e, por consequência, reduzam as demandas psicológicas. Melhores condições de trabalho, em todas as fases da vida do trabalhador, repercutirão não somente na saúde desses, mas na instituição e na equipe, resultando em menor absenteísmo e presenteísmo (Prochnow et al., 2013).

Não obstante as características pessoais, as fases de estagnação e deterioração profissional não devem ser desvinculadas do propósito da instituição, como forma de potencializar essas características e abafar o crescimento profissional de diversas pessoas. A organização aplica recursos, como a manipulação da intimidação, para defender seus interesses socioeconômicos. O estímulo de comportamentos que condicionam a regras e padrões da cultura organizacional, acomodando os trabalhadores em seus contextos, pode ser justificativa da estagnação e deterioração profissional. As práticas desse universo desenvolvem-se diante de novas ferramentas de gestão. Guiados pela necessidade constante de aumento da produtividade e geração de lucros, o isolamento e a exclusão daqueles que se constituem como obstáculos para alcance dos fins serão oprimidos mediante a pressão institucionalizada e, grande parte das vezes, pautada no silêncio.

Para Antunes (2018, p. 44): “[...] essa lógica que estamos descrevendo é fortemente destrutiva em relação ao mundo do trabalho, a contrapartida esparramada pelo ideário empresarial tem de ser amenizada e humanizada. Segundo este autor, um novo dicionário laboral ressignifica o conteúdo autêntico das palavras, deturpando-as no cotidiano do trabalho".

O Quadro 1 mostra várias palavras e seus significados baseados no estudo de Antunes (2018) como as mais significativas na forma de "Novo dicionário laboral", que mostra o status quo desejável nas equipes de Enfermagem. 
Quadro 1. Novo dicionário laboral.

\begin{tabular}{|c|c|}
\hline Palavras & Significado* \\
\hline Agilidade & Característica, particularidade ou estado de ágil; presteza ou ligeireza. \\
\hline Colaborador & Que ou aquele que colabora, que ajuda o outro em suas funções. \\
\hline Colaborativo & $\begin{array}{l}\text { Que envolve ou contém colaboração, auxílio, ajuda; cooperativo. } \\
\text { Produzido em conjunto com outras pessoas; desenvolvido com a contribuição de: "Meu trabalho é } \\
\text { supercolaborativo, feito com o intuito de facilitar a vida de milhões de pessoas". }\end{array}$ \\
\hline Desempenho & Modo com alguém ou alguma coisa se comporta tendo em conta sua eficiência, seu rendimento. \\
\hline Disponível & $\begin{array}{l}\text { Que se encontra ao dispor, à disposição (condição física ou espiritual: "Tinha boa disposição para o } \\
\text { trabalho".). } \\
\text { Tendência natural que leva alguém a fazer alguma coisa. (boa condição mental ou física) } \\
\text { Desimpedido; que não está impedido; que está desocupado. }\end{array}$ \\
\hline Eficiência & $\begin{array}{l}\text { Capacidade de realizar tarefas ou trabalhos de modo eficaz e com o mínimo de desperdício; } \\
\text { produtividade. } \\
\text { Tendência ou aptidão para ser efetivo; capacidade de realizar ou desenvolver alguma coisa } \\
\text { demonstrando eficácia; efetividade. }\end{array}$ \\
\hline Empoderamento & $\begin{array}{l}\text { Ação de tornar-se poderoso, de passar a possuir poder, autoridade, domínio sobre. } \\
\text { Ação ou efeito de empoderar, de obter poder. }\end{array}$ \\
\hline Flexibilidade & $\begin{array}{l}\text { Flexibilidade é a característica do que é flexível, ou seja, aquilo que consegue se dobrar com } \\
\text { facilidade; maleável. } \\
\text { No sentido figurado da palavra, a flexibilidade de um indivíduo é a qualidade de compreender, } \\
\text { aceitar ou assumir as opiniões, ideias ou pensamentos de outras pessoas. Normalmente, as pessoas } \\
\text { flexíveis são consideradas dóceis e diplomáticas. } \\
\text { A capacidade de um indivíduo conseguir realizar várias atividades ou ocupações ao mesmo tempo } \\
\text { pode ser considerada um tipo de flexibilidade. }\end{array}$ \\
\hline Governabilidade & $\begin{array}{l}\text { Característica daquilo que é governável. } \\
\text { Circunstância que denota estabilidade social, financeira, política e possibilita, ao Poder Executivo, } \\
\text { exercitar suas funções para governar de forma estável. }\end{array}$ \\
\hline Meta & $\begin{array}{l}\text { Aquilo que se pretende alcançar; objetivo, finalidade. } \\
\text { Finalização de alguma coisa; termo, limite: "A meta já foi entregue". }\end{array}$ \\
\hline Sinergia & Ação simultânea; esforço coletivo; cooperação. \\
\hline Parceiro & 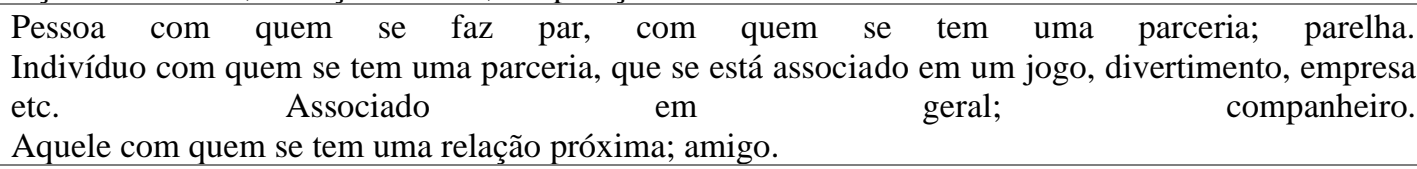 \\
\hline Performance & Modo como alguém se comporta ou atua na execução de alguma coisa. \\
\hline Protagonismo & $\begin{array}{l}\text { Qualidade da pessoa que se destaca em qualquer situação, acontecimento, exercendo o papel mais } \\
\text { importante dentre os demais. }\end{array}$ \\
\hline Resiliência & $\begin{array}{l}\text { Propriedade dos corpos que voltam à sua forma original depois de terem sofrido deformação ou } \\
\text { choque. } \\
\text { Figurado. Capacidade de quem se adapta às intempéries, às alterações ou aos infortúnios. Figurado. } \\
\text { Tendência natural para se recuperar ou superar com facilidade os problemas que aparecem. Física. } \\
\text { Característica mecânica que define a resistência dos choques de materiais. }\end{array}$ \\
\hline Sustentabilidade & $\begin{array}{l}\text { Conceito que, relacionando aspectos econômicos, sociais, culturais e ambientais, busca suprir as } \\
\text { necessidades do presente sem afetar as gerações } \\
\text { Qualidade ou propriedade do que é sustentável, do que é necessário à conservação da vida. }\end{array}$ \\
\hline Vestir a camisa & $\begin{array}{l}\text { Se dedicar a algo (sobretudo com relação ao trabalho); colocar seu coração e todo seu esforço em } \\
\text { algo ou alguém. }\end{array}$ \\
\hline
\end{tabular}

Fonte: *Ferreira (2000).

Requeridas pelo mercado, novas formas de gestão impõem o poder de forma não impositiva por cobranças não explicitadas. Alívio seria se essa nova ordem não fosse transformada em sofisticada, ou seja, o poder impositivo agora é inoculado pela sofisticação (Barreto \& Heloani, 2015). A psicopolítica de Han (2015) explica uma forma de domínio em que o ser humano se submete a si próprio sem ter consciência disso e torna-se seu próprio controlador. Assim, as resistências que devem ser superadas referem-se a processos psíquicos e mentais e não a físicos. 
Poder fazer e cobrar-se a si mesmo torna-se força motriz ao ser humano a ser captor de si próprio. Ele próprio impõe, a si mesmo, as suas condições e metas de produção. Nesse cenário, novas patologias surgem no espaço laboral como a síndrome do esgotamento profissional, a depressão e a ansiedade (Han, 2015).

Em A sociedade do cansaço (2015), a sociedade disciplinar de Foucault foi substituída pela atual sociedade do desempenho. Os sujeitos da obediência são agora os sujeitos de desempenho e produção. A característica principal dessa nova sociedade é o poder ilimitado, como a nova ordem do "Yes, we can". No lugar da proibição, mandamento ou lei, entram o projeto, a iniciativa e a motivação. A sociedade de Foucault, dominada pelo não, gera loucos e delinquentes; a sociedade do desempenho, ao contrário, produz depressivos e fracassados (Han, 2015).

Para elevar a produtividade, o paradigma da disciplina é substituído pelo do desempenho ou pelo esquema positivo do poder. A positividade do poder é bem mais eficiente que a negatividade do dever. O sujeito do desempenho é mais rápido e mais produtivo que o sujeito da obediência. Segundo Han (2015, p. 29-30):

O sujeito de desempenho está livre da instância externa de domínio que o obriga a trabalhar ou que poderia explorálo. É senhor soberano de si mesmo. Assim, não está submisso a ninguém ou está submisso apensa a si mesmo. É nisso que ele se distingue do sujeito de obediência. A queda da instância dominadora não leva à liberdade. Ao contrário, faz com que liberdade e coação coincidam. O excesso de trabalho e desempenho agudiza-se na autoexploração do outro, pois caminha de mão dadas com o sentimento de liberdade. O explorador é ao mesmo tempo explorado. Agressor e vítima não podem mais ser distinguidos. Essa autorreferencialidade gera uma liberdade paradoxal que, em virtude das estruturas coercitivas que lhe são inerentes, se transforma em violência. Os adoecimentos psíquicos da sociedade de desempenho são precisamente as manifestações patológicas dessa liberdade paradoxal.

Para a adaptação à cultura organizacional e/ou ideologia da instituição, os profissionais são direcionados a imposições de horários infindáveis, ritmos acelerados de trabalho, formação, informação, aprendizagem, nível de instrução e diploma, experiência, rapidez, aquisição de conhecimentos teóricos e práticos. Para tais fins, o medo da incompetência, a pressão para trabalhar mal e não ter esperança em ser reconhecido são os meios utilizados pelas gestões modernas (Dejours, 2012).

Segundo Barreto e Heloani (2015b, p. 546):

O mais importante é ultrapassar a meta e dar produtividade, não importa como, ou melhor: não se tolera os improdutivos, independentemente das causas. Não se tolera os críticos das jornadas extenuantes. Não se admite que adoeçam. Os dirigentes sindicais e até os filiados são recusados ou mesmo negados como categoria. São novos tempos que impõem mudanças de comportamento, mentalidade e cultura. Entretanto, uma hierarquia rígida, mesmo que travestida de autonomia subsiste.

Testemunham-se, dessa forma, alargamentos da precarização, informalidade, subemprego, desemprego, trabalhadores intermitentes, eliminação de postos de trabalho e subsequentes em pessoas que trabalham com os direitos preservados. Para Antunes (2018, p. 44):

Quando entram em cena os enxugamentos, as reestruturações, as inovações tecnológicas da indústria 4.0, enfim, as reorganizações comandadas pelos que fazem a gestão de pessoas e pelos que formulam as tecnologias do capital, o que temos é para tentar amenizar esse flagelo, propaga-se em todo canto um novo subterfúgio: o empreendedorismo, no qual todas as esperanças são apostadas e cujo desfecho nunca se sabe qual será.

Importante ressaltar que as consequências da violência contra os profissionais de Enfermagem repercutem em seu trabalho, de forma a reduzir a força de trabalho, adoecendo e desgastando a equipe, o que reflete diretamente na qualidade do cuidado prestado (Silva et al., 2020). 


\section{Considerações Finais}

O objetivo principal deste estudo foi compreender o cotidiano de gestores da Enfermagem quanto à violência no ambiente de trabalho.

Como responsável pelo processo de trabalho gerencial, referencia-se, ao profissional enfermeiro, a mediação entre a equipe de Enfermagem e toda a equipe de saúde. A incorporação tecnológica intensa, as mudanças no mercado de trabalho, que exige profissionais polivalentes e com maior qualificação técnica e os novos padrões de gestão do trabalho exigem, dos enfermeiros, maior integração de funções. Soma-se a este contexto a pressão organizacional imposta às lideranças para cumprir metas já instituídas, além de garantir adequações em seus postos e na equipe de trabalho de acordo com as exigências do mercado. As relações profissionais modificam-se e refletem nas relações interpessoais, que extrapolam o conflito e podem ocasionar sofrimento no ambiente de trabalho.

A análise dos discursos permitiu compreender a experiência de gestores de Enfermagem nos seus distintos ambientes laborais em relação a situações que envolvem riscos à saúde do trabalhador e a qualidade e segurança da assistência prestada. Os resultados apresentados neste estudo direcionam para um repensar nas condições de trabalho e nas possíveis estratégias para transformar o cenário no que tangencia às situações de violência a proporcionar ambientes saudáveis para se trabalhar.

\section{Referências}

Antunes, R. (2018). O privilégio da servidão: o novo proletariado de serviços na era digital. Bomtempo.

Almeida, M. C. P., Fortuna, C. M., Pereira, M. J. B., Mishima, S. M., \& Villa, T. C. S. (1994). Gerência na rede básica de serviços de saúde: processo de trabalho. Revista Brasileira de Enfermagem, 47(3), 278-286.

Barreto, M. M. S., \& Heloani, R. (2015). Violência, saúde e trabalho: a intolerância e o assédio moral nas relações laborais. Serviço Social \& Sociedade, 123, 544-546.

Dejours, C. (2012). A banalização da injustiça social. (7a ed). FGV.

Felli, V. E. A., Costa, T. F., Baptista, P. C. P., Guimarães, A. L. O., \& Anginoni, B. M. (2015). Exposição dos trabalhadores de enfermagem às cargas de trabalho e suas consequências. Revista da Escola de Enfermagem da USP, 49(2), 98-105.

Ferreira, A. B. H. (2000). Dicionário da língua portuguesa. (3a ed).

Hagopian, E. M., Sousa, R. D., \& Bianco, M. D. (2020). Constituição de um grupo de estudo sobre violência no trabalho: relato de experiência. Farol - Revista de Estudos Organizacionais e Sociedade, 7(19), 768-800.

Han, B. C. (2015). Psicopolítica. Barcelona: Herder.

Han, B. C. (2015). Sociedade do cansaço. (2a ed). Vozes.

Hashizume, C. M. (2014). Violência simbólica no trabalho: considerações exploratórias sobre a nova ontologia do trabalhador na pós-modernidade. Revista Ambivalências, 2(4), 137-150.

Machado, M. H., Aguiar Filho, W., Lacerda, W. F., Oliveira, E., Lemos, W., Wermelinger, M., Vieira, M., Santos, M. R., Souza Junior, P. B., Justino, E., \& Barbosa, C. (2016). Características gerais da enfermagem: o perfil sóciodemográfico. Enfermagem em Foco, 7(esp), 9-14.

Medeiros, J. B. (2008). Redação científica: a prática de fichamento, resumos, resenhas. (10a ed.). Atlas.

Minayo, M. C. S. (2013). O desafio do conhecimento: pesquisa qualitativa em saúde. Hucitec.

Pagés, M., Bonetti, M., Gaulejac, V., \& Descendre, D. (2005). O poder das organizações. Atlas.

Prochnow, A., Magnago, T. S. B. S., Urbanetto, J. S., Beck, C. L. C., Lima, S. B. S., \& Greco, P. B.T. (2013). Capacidade para o trabalho na enfermagem: relação com demandas psicológicas e controle sobre o trabalho. Revista Latino-Americana de Enfermagem, 21(6), $1298-1305$.

Silva, B. A., Telles, V. R., \& Tavares, M. M. (2020). A interferência da violência na rotina de trabalho de enfermagem. Pesquisa, Sociedade $e$ Desenvolvimento, 9(8), e765985636.

Teixeira, E. (2008). Abordagens qualitativas: trilhas para pesquisadores em saúde e enfermagem. Martinari. 